\title{
ARTICLE
}

Received 1 Jun 2010 | Accepted 26 Jan 2011 | Published 22 Feb 2011

DOI:10.1038/ncomms1209

\section{Ionic polypeptides with unusual helical stability}

\author{
Hua Lu', Jing Wang², Yugang Bai', Jason W. Lang', Shiyong Liu³, Yao Lin² \& Jianjun Cheng'
}

Water-soluble peptides that adopt stable helical conformations are attractive motifs because of their importance in basic science and their broad utility in medicine and biotechnology. Incorporating charged amino-acid residues to improve peptide solubility, however, usually leads to reduced helical stability because of increased side-chain charge repulsion, reduced side-chain hydrophobicity and the disruption of intramolecular hydrogen bonding. Here, we show that water-soluble, ultra-stable $\alpha$-helical polypeptides can be produced by elongating charge-containing amino-acid side chains to position the charges distally from the polypeptide backbone. The strategy has been successfully applied to the design and synthesis of watersoluble polypeptides bearing long, charged side chains and various functional moieties that possess unusual helical stability against changing environmental conditions, including changes in the $\mathrm{pH}$ and temperature and the presence of denaturing reagents.

\footnotetext{
${ }^{1}$ Department of Materials Science and Engineering, University of Illinois at Urbana-Champaign, Urbana, Illinois 61801, USA. ${ }^{2}$ Department of Chemistry, Polymer Program, Institute of Materials Science, University of Connecticut, Storrs, Connecticut 06269, USA. ${ }^{3}$ Department of Polymer Science and Engineering, CAS Key Laboratory of Soft Matter Chemistry, Hefei National Laboratory for Physical Sciences at Microscale, University of Science and Technology of China, Hefei, Anhui 230026, China. Correspondence and requests for materials should be addressed to J.C. (email: jianjunc@illinois.edu) or to Y.L. (email: ylin@ims.uconn.edu).
} 
T he $\alpha$-helix, the most prevalent type of secondary structure found in proteins, forms the cornerstone of the three-dimensional architecture of proteins and regulates numerous biological activities ${ }^{1}$. As a motif with a unique folding/unfolding property and a rigid rod-like morphology, the $\alpha$-helix has been the subject of intense study and has been broadly used as a building block in the design of therapeutics and molecular assemblies ${ }^{2-12}$. Polypeptides bearing an $\alpha$-helical conformation can be made entirely of hydrophobic amino acids with high helical propensities (for example, Ala and Leu $)^{13-15}$. However, the usefulness of these structures is limited because of their poor aqueous solubility and processability. In the past, interest has been largely focused on the design and synthesis of water-soluble $\alpha$-helical polypeptides or peptide motifs that usually contain a handful of charged amino acids (for example, Glu or Lys). Yet, the incorporation of charged residues into polypeptides often results in increased side-chain electrostatic repulsion ${ }^{3,16-18}$, which tends to destabilize the helical conformation. In the extreme context in which the polypeptides are made exclusively of amino acids bearing charged side chains, such as poly(L-glutamate) (PLG) or poly(L-lysine) (PLL), they adopt random coil conformations when their side chains are charged.

As increasing the water solubility by introducing charge groups and enhancing the helical stability of polypeptides are often contradictory to each other, it has been a routine strategy to integrate both water-soluble and helix-stabilizing motifs in the peptide structure to design water-soluble helical peptides. Often, peptides are designed to have the charged amino-acid residues placed on one side of the helix surface and the residues responsible for stabilizing the helix through side-chain hydrophobic interactions ${ }^{18}$, salt bridges ${ }^{19}$ or tethering ${ }^{20}$ placed on the opposite side of the helix surface. These strategies require the design of peptides with specific sequences and/or involve tedious chemistries of polypeptide side chains that are typically difficult to control. For polypeptides made by polymerization rather than through stepwise synthesis, the above-mentioned helix-stabilization strategies cannot be applied.

Water-soluble polypeptides that adopt stable $\alpha$-helical conformations have long been sought after. Tremendous efforts have been focused on introducing neutrally charged, hydrophilic functional group $s^{21}$ or moieties ${ }^{22}$. For instance, poly $(N$-hydroxyalkyl-Lglutamine $)^{21}$, derived from aminolysis of poly(L-glutamate esters), was found to be water soluble because of its pendant hydroxyl groups. It adopts a moderately high helical structure (up to $\sim 65 \%$ helicity) in aqueous solution ${ }^{21}$. Deming and co-workers reported the synthesis of PLL-containing pendant oligoethyleneglycol moieties using the ring-opening polymerization (ROP) of oligoethyleneglycolcontaining lysine $\mathrm{N}$-carboxyanhdyride (NCA $)^{22}$. The resulting oligoethyleneglycol-graft PLL showed excellent water solubility and up to $\sim 100 \%$ helical structure in $\mathrm{pH} 7$ water at $25^{\circ} \mathrm{C}$. These polypeptides were designed in a manner to introduce water-soluble motifs on an $\alpha$-helical structure in the absence of electrostatic perturbations. To our knowledge, charged, water-soluble polypeptides that adopt stable $\alpha$-helical conformations, that is, $\alpha$-helical polypeptide electrolytes ( $\alpha$ HPEs), have never been reported.

When analysing helix-forming amino acids, it can be found that Ala and its three analogues, $\alpha$-aminobutyric acid, norvaline and norleucine (Fig. 1a), have identical helical propensitie ${ }^{23}$, indicating that the linear elongation of an amino-acid side chain with hydrocarbons does not affect its helix-forming capability. When a charged group (for example, $\mathrm{COO}^{-}$or $\mathrm{NH}_{3}{ }^{+}$) is placed at the termini of the hydrocarbon side chains of these amino acids, however, substantially reduced amino-acid helix propensity scales are noted ${ }^{24}$. Interestingly, the helix propensity of $\mathrm{Asp}^{-}, \mathrm{Glu}^{-}, \mathrm{Lys}^{+}$and $\mathrm{Arg}^{+}$, the four charged natural amino acids with straight side chains (Fig. 1b), is strongly correlated with the length of the hydrocarbon side chain; the longer the hydrocarbon side chains (the further away the charge is from the backbone), the higher the helix-forming propensity. Their helical propensities are in the order of $\mathrm{Arg}^{+}>\mathrm{Lys}^{+}>\mathrm{Glu}^{-}>\mathrm{Asp}^{-}$, where the charge is $6,5,4$ or $3 \sigma$-bonds away from the peptide backbone, respectively (Fig. 1b) (ref. 24). We reasoned that the differences in their helix-forming propensities could be partly due to the differences in charge density on the helical surfaces, with the poly $\left(\mathrm{Arg}^{+}\right)$ helix being the lowest (the largest helical surface area, the weakest electrostatic repulsion) and poly( $\mathrm{Asp}^{-}$) being the highest (the smallest helical surface area, the strongest electrostatic repulsion) if they are both formed (Fig. 1c). We postulated that when the charge is moved further away from the peptide backbone to reduce the overall charge density on the helical surface and charge repulsion, at some point the charge may have a negligible effect on the helical propensity of amino acids with long, straight side chains. As a result, these polypeptides with charges that are distally situated from the peptide backbone on a hydrophobic side chain may simultaneously maintain water solubility and stable helical structures (Fig. 1d).

In this study, we prepared a series of PLG analogues with extented, hydrophobic side chains bearing a terminal, positively charged amine group. When the amine group was placed $11 \sigma$-bonds away from the polypeptide backbones, the corresponding polypeptide bearing positive charges on its side chains indeed showed remarkable $\alpha$-helical conformations crossing a broad range of $\mathrm{pH}$ (from 1 to 10). This design principle has been applied to the synthesis of a handful of polypeptides with similar side-chain strucutres and has been confirmed as these polypeptides all possess $\alpha$-helical conformations with unusual helical stability against changing environmental conditions.

\section{Results}

Poly(L-glutamates) with charged and long side chains. To test this hypothesis, we prepared a $57 \mathrm{mer}$ of $\operatorname{poly}(\gamma$-(3-aminopropyl)L-glutamate) $\left(\mathrm{PAPG}_{57}\right)$, a $50 \mathrm{mer}$ of poly $(\gamma$-(5-aminopentanyl)L-glutamate) $\left(\mathrm{PAPTG}_{50}\right)$ and a 57 mer of poly $(\gamma-(6$-aminohexyl)-Lglutamate) $\left(\mathrm{PAHG}_{57}\right)$ through the ROPs of $\gamma$-benzyl-L-glutamate $N$-carboxyanhydride (Glu-NCA) ${ }^{25-27}$ followed by removing the benzyl ester PBLG side chains and grafting the corresponding amino alcohol to the pendant carboxylate groups of PLG by the formation of ester bonds (Fig. 2a, Supplemenary Figs S1-S3). PAPG $_{57}$, PAPTG $_{50}$ and $\mathrm{PAHG}_{57}$ contain hydrophobic side chains with different lengths and a terminal, charged amine group $\left(-\mathrm{NH}_{3}{ }^{+}\right)$situated 8,10 and $11 \sigma$-bonds, respectively, away from its backbone. Compared with the circular dichroism (CD) spectrum of a 75 mer of PLL $\left(\mathrm{PLL}_{75}\right)$ at $\mathrm{pH} 3$, which is known to adopt a random coil conformation, the $\mathrm{CD}$ spectrum of $\mathrm{PAPG}_{57}$ at $\mathrm{pH} 3$ showed some characteristics of an $\alpha$ helical conformation (Fig. 3a). A minimum at $222 \mathrm{~nm}$ with a molar ellipticity $[\theta]_{222}$ ) value of $-3,100 \mathrm{~cm}^{2} \mathrm{deg} \mathrm{dmol}^{-1}$ was observed, which corresponds to $\sim 16 \%$ of helical content ${ }^{28}$; the other expected minimum around $208 \mathrm{~nm}$ was not obvious. The characteristic double minima of the CD spectrum of an $\alpha$-helical conformation became more obvious in PAPTG $_{50}$ with its helical content at $\mathrm{pH} 3$ increased to $\sim 29 \%$ with a $[\theta]_{222}$ value of $-7,400 \mathrm{~cm}^{2} \mathrm{deg} \mathrm{dmol}^{-1}$. For $\mathrm{PAHG}_{57}$ that has the largest space between the charged, terminal amine group and the polypeptide backbone, it adopts an $\alpha$-helical conformation, as shown in its CD spectrum with characteristic double minima at 222 and $208 \mathrm{~nm}$ and has a helical content of $45 \%$. Apparently, the hypothesis of creating water-soluble, charged, helical polypeptides by placing charges distally situated from the peptide backbone is demonstrated to be correct.

$\mathrm{PAHG}_{57}$ showed remarkable $\mathrm{pH}$-independent helical stability at $\mathrm{pH}$ values ranging from 1 to 10 , with $-[\theta]_{222}$ value at $14,000 \mathrm{~cm}^{2}$ deg $\mathrm{dmol}^{-1}$ for $\mathrm{pH} 1$ and at $14,200 \mathrm{~cm}^{2} \mathrm{deg} \mathrm{dmol}^{-1}$ for $\mathrm{pH} 10(\approx 44-45 \%$ helical content; Fig. 3b, Supplementary Fig. S4). Further increases in $\mathrm{pH}(\mathrm{pH}>11)$ resulted in deprotonation of the positively charged amino group on the side chain and a decreased solubility of $\mathrm{PAHG}_{57}$. $\mathrm{PAHG}_{57}$ also showed a lack of concentration dependence of its $-[\theta]_{222}$ and $-[\theta]_{208}$ values in helix-forming conditions, suggesting 
a<smiles>C[C@H]([NH3+])C(=O)[O-]</smiles>

Alanine<smiles>CCC([NH3+])C(=O)[O-]</smiles>

$\alpha$-Aminobutyric acid<smiles>CCCC(C(=O)[O-])[N+](=O)[O-]</smiles><smiles>CCCC[C@H]([NH3+])C(=O)[O-]</smiles>

Norleucine c

Shorter side chain higher surface charge density

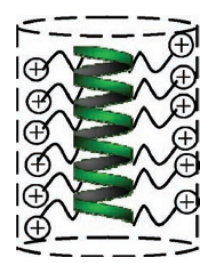

$\alpha$-Helix (disfavoured)
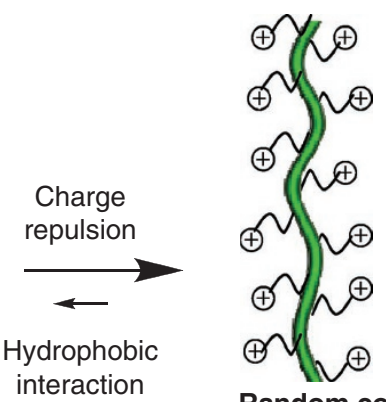

Random coil

(favoured)

b Distance between the charge and the $\alpha$-carbon on the backbone
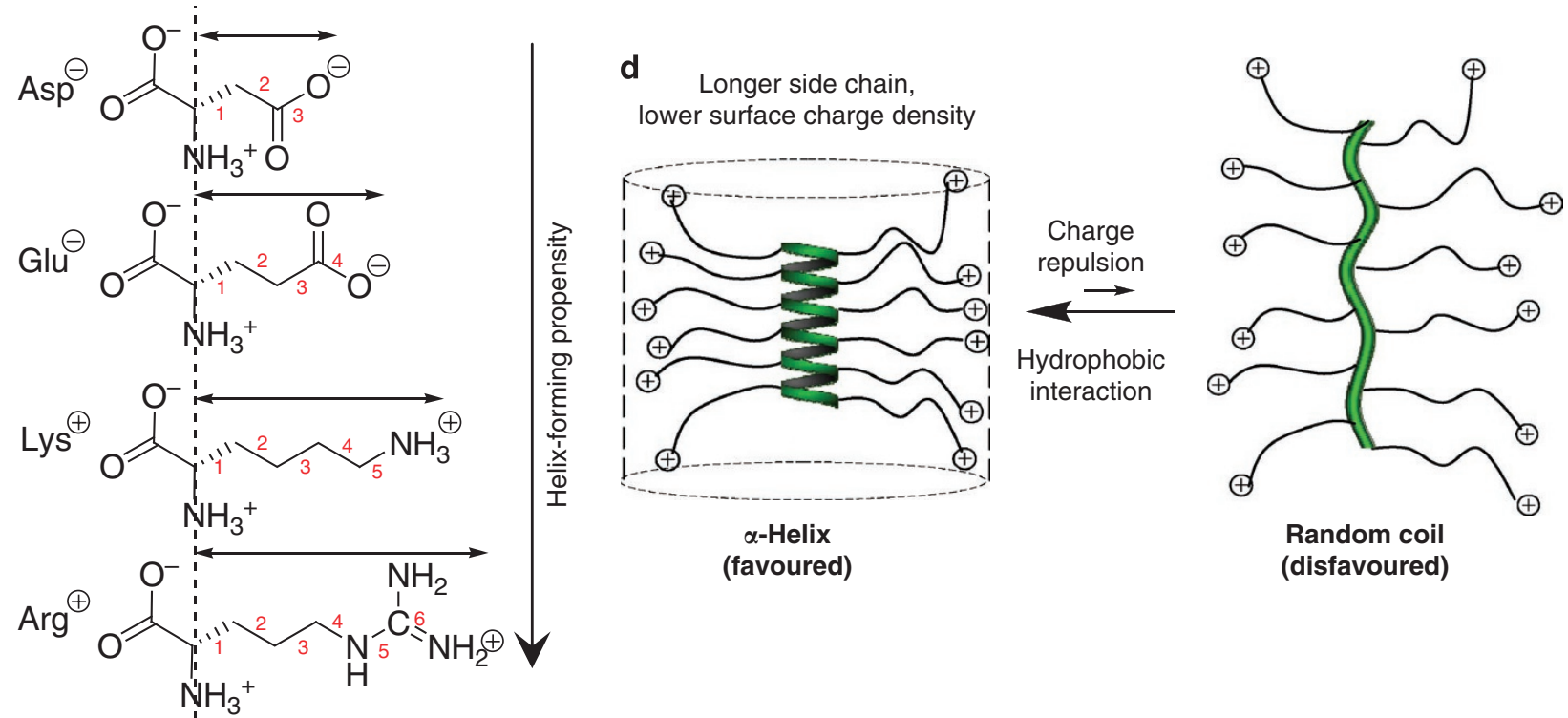

Figure 1 | Amino acids' and their helix-forming properties. (a) Illustration of amino acids containing linear hydrocarbon side chains with variable lengths. (b) Illustration of four amino acids with charged side chains (Asp, Glu, Lys and Arg) and the correlation of their helix-forming propensity with the distance between the side-chain charge and the $\alpha$-carbon. (c) Illustration of polypeptides with short, charged side chains and the postulated helix-to-random coil transition because of side-chain charge repulsion. (d) Illustration of polypeptides with long, charged side chains and postulated random coil-to-helix transition because of reduced side-chain charge repulsion.

that it remains monomeric in solution (Fig. 3c, Supplementary Fig. S5). PAHG $_{57}$ showed temperature-dependent helical stability as its $-[\theta]_{222}$ value decreased $45 \%$ from $15,900 \mathrm{~cm}^{2} \mathrm{deg} \mathrm{dmol}^{-1}$ at $4{ }^{\circ} \mathrm{C}$ to $8,700 \mathrm{~cm}^{2} \mathrm{deg} \mathrm{dmol}^{-1}$ at $70^{\circ} \mathrm{C}$ (Fig. 3d, Supplementary Fig. S6). It exhibited remarkable stability against the change in the $\mathrm{NaCl}$ concentration and remained nearly unchanged in its $-[\theta]_{222}$ value when the $\mathrm{NaCl}$ concentration was increased from 0 to $4.7 \mathrm{M}$ at $\mathrm{pH} 3$ at $25^{\circ} \mathrm{C}$, a concentration for which all of the charges should have been screened, which is distinctly different from PLL $_{75}$ (Fig. 3e, Supplementary Fig. S7). These experiments further demonstrate that the surface charges of $\mathrm{PAHG}_{50}$ have minimal effects on its helical stability. The helical conformation of $\mathrm{PAHG}_{57}$ was gradually disrupted at increased concentrations of strong denaturing reagents such as urea and methanesulfonic acid (MSA) (Fig. 3f, Supplementary Figs S8-S9).

To elucidate the effect of the side-chain hydrophobicity and the charge on the formation and stabilization of $\alpha$-helical conformations, we synthesized a 50mer of poly $(\gamma$-(2-aminoethyl)-ethyleneglycol-L-glutamate) $\left(\right.$ PAEG $\left._{50}\right)$ (Fig. 2a, Supplementary Fig. S10). PAEG 50 has exactly the same structure as $\mathrm{PAPTG}_{50}$ except that one ' $\mathrm{CH}_{2}$ ' unit of PAPTG ${ }_{50}$ was replaced by an 'O' in $\mathrm{PAEG}_{50}$, which makes PAEG more hydrophilic than PAPTG. The CD analysis showed that PAEG adopts a random coil structure at $\mathrm{pH} 3$ when the terminal amine is protonated (Fig. 3a), which underscores the importance of the hydrophobicity of the side chains connecting the terminal charge and the backbone on the stabilization of the $\alpha$-helical conformation. Interestingly, when the side chain of PAEG ${ }_{50}$ was elongated by inserting a hydrophilic, hepta(ethylene glycol) to further extend the charged amine group, a random coil-to-helix transition was observed and the resulting $\operatorname{poly}((\gamma$-(2-aminoethyl $)$-heptaethyleneglycol $)-\mathrm{L}$ glutamate) $\left(\right.$ PAHEG $\left._{50}\right)$ (Supplementary Fig. S11) adopts an $\alpha$-helical conformation at $\mathrm{pH}$ 3. These experiments suggest that the reducing helical surface charge density (reducing side-chain charge repulsion) is crucial to the stabilization of $\alpha$-helical conformation.

Design, synthesis and conformation analysis of poly $(\gamma$-(4-vinylbenzyl)-L-glutamate)s. Motivated by this discovery, we next tested whether this helix-stabilization strategy could be generally applied to designing water-soluble, $\alpha$ HPEs that contain charged secondary amines with various functional moieties attached to the amine. To avoid the harsh deprotection chemistry and low conjugation activity illustrated in Figure 2a, we attempted and successfully developed a highly efficient conjugation strategy that involves the ROP of $\gamma$-(4-vinylbenzyl)-L-glutamate NCA (VB-Glu-NCA) to yield poly ( $\gamma$-(4-vinylbenzyl)-L-glutamate) (PVBLG, Supplementary Fig. S12) followed by the formation of poly $(\gamma$-(4-aldehydebenzyl)-L-glutamate) (PABLG, Supplementary Fig. S13) through the ozonolysis 


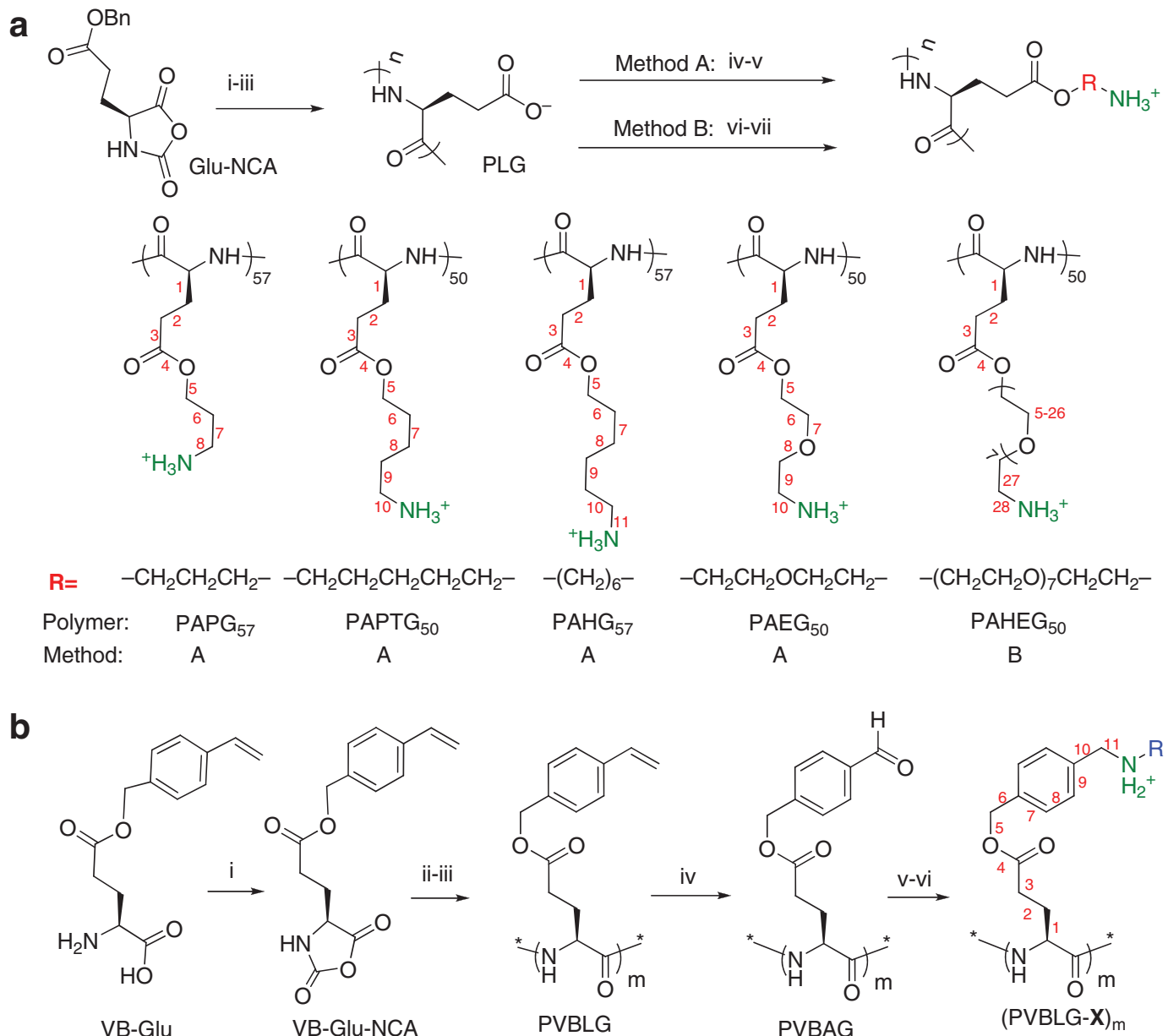

$X\left(\mathrm{R}-\mathrm{NH}_{2}\right)$
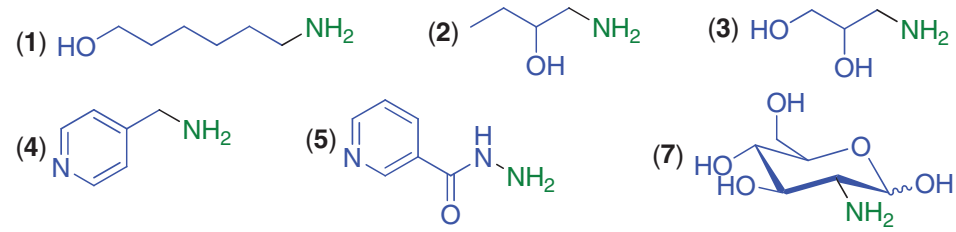

(6)<smiles>Nc1ccc(OCCOCCOCCOCCO)c(OCCO)c1</smiles>

Figure $\mathbf{2}$ | Synthesis of polypeptides with charged side chains. (a) Synthesis of PAPG, PAPTG, PAHG, PAEG and PAHEG. The brief reaction condition of each step was listed below: (i) hexamethyldisilazane (HMDS)/DMF; (ii) CBZ-Cl; (iii) HBr; (iv) OH-R-NH(Boc), $\mathrm{BOP}-\mathrm{Cl}$; (v) $\mathrm{HCl}$; (vi) OH-R-N 3 , $\mathrm{BOP}-\mathrm{Cl}$; (vii) 1. $\mathrm{PPh}_{3}, \mathrm{CHCl}_{3} ;$ 2. $\mathrm{NH}_{3}-\mathrm{H}_{2} \mathrm{O}$. (b) Synthesis of PVBLG-X. The brief reaction condition of each step was listed below: (i) phosgene; (ii) HMDS/DMF/ nitrobenzene; (iii) benzyl chloroformate/diisopropyl ethyl amine/tetrabutylammonium floride; (iv) $\mathrm{O}_{3} / \mathrm{CHCl}_{3} /-78^{\circ} \mathrm{C} ; \mathrm{v} . \mathbf{X} /[\mathrm{H}](\boldsymbol{X}=\mathbf{1}-7) ;(v i) \mathrm{HCl}$.

of PVBLG, and hydroamination of the PABLG with 6-amino-1hexanol (1) to give the desired products (PVBLG-1) $m$, where ' $m$ ' corresponds to the degree of VB-Glu-NCA polymerization (Fig. 2b, Supplementary Fig. S14). The positive charge of (PVBLG-1) $)_{m}$ was placed exactly $11 \sigma$-bonds away from its backbone, just like PAHG. VB-Glu-NCA can be readily prepared and purified by crystallization on a multi-gram scale ${ }^{29-30}$ and can be polymerized in a highly controlled manner to yield PVBLGs using $N$-trimethylsilyl ( $N$-TMS) amine initiators previously developed by our group (Fig. 4a) (ref. 25). The obtained $M_{\mathrm{n}}$ values of the PVBLGs were in excellent agreement with the expected molecular weights (MWs; <5-15\% MW deviation), and the polydispersities (PDIs) of the PVBLGs were all below 1.10 (Fig. 4a). Such hexamethyldisilazane-mediated VB-Glu-NCA polymerizations are highly reproducible. We repeated the polymerization at a monomer-to-initiatior (VB-Glu-NCA/hexamethyldisilazane) ratio of 100:1 in three separate experiments using the VB-Glu-NCA from different batches, the obtained average $M_{\mathrm{n}}$ value was $24.3 \pm 2.7 \times 10^{3} \mathrm{~g} \mathrm{~mol}^{-1}$, which was in almost perfect agreement with the expected MW $\left(24.5 \times 10^{3} \mathrm{~g} \mathrm{~mol}^{-1}\right)$. The MWs of PVBLG showed linear correlation with the conversions of VB-Glu-NCA and agreed perfectly with the expected MWs (Fig. 4b), demonstrating that PVBLG chains were propagated through living chain ends ${ }^{27}$. PVBLGs are very soluble in common organic solvents (for example, THF, $\mathrm{CHCl}_{3}$ and DMF), which facilitates their side-chain modification to yield (PVBLG-1) ${ }_{m}$ with over 95\% grafting efficiency (entries 1-6 in Table 1).

$(\text { PVBLG-1 })_{60}$ is highly water soluble at $\mathrm{pH} 1-10\left(>40 \mathrm{mg} \mathrm{ml}^{-1}\right)$ and adopts an $\alpha$-helical conformation with a $-[\theta]_{222}$ value of $32,600 \mathrm{~cm}^{2} \mathrm{deg} \mathrm{dmol}^{-1}$ for $\mathrm{pH}$ values as low as 1 (Fig. $3 \mathrm{~g}$, Supplementary Fig. S15). The high helical content of (PVBLG-1) 60 as compared with PAHG $_{57}$ is presumably because of its increased sidechain hydrophobic interactions. The $-[\theta]_{222}$ value of (PVBLG-1) $)_{60}$ 

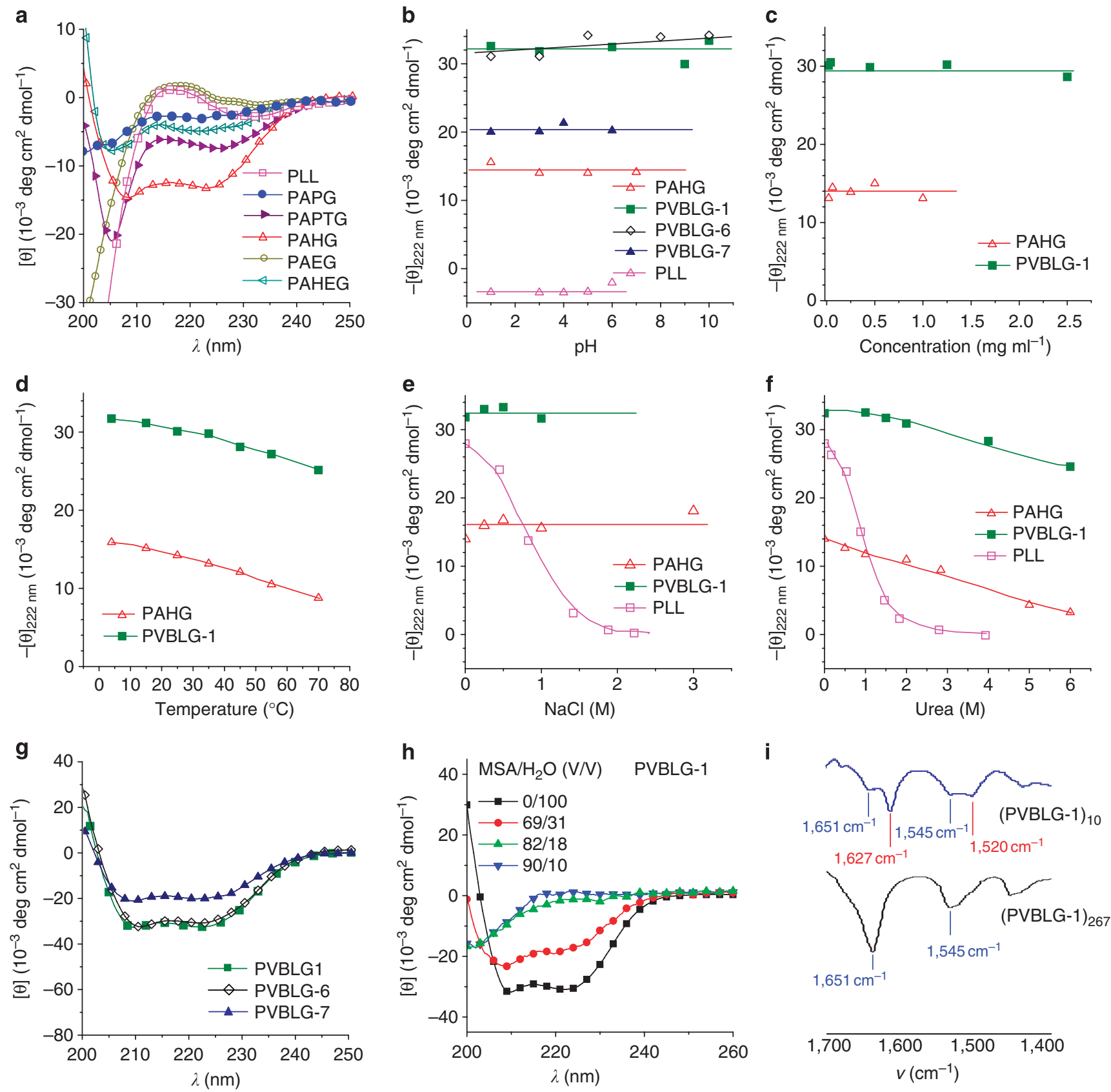

Figure 3 | Characterization of charged polypeptides. PAHG and PVBLG-X, polypeptides with long, charged, hydrophobic side chains, adopt very stable $\alpha$-helica conformations at low $\mathrm{pH}$, at elevated temperature, or in solution containing high concentration of salt or denaturing agents (for example, urea or MSA). (a) CD spectra of various polypeptides bearing charged side chains (PAPG, PAPTG, PAHG, PAEG and PAHEG) in aqueous solution at pH 3. The mean residue molar ellipticity was calculated by following literature-reported formulas: Ellipticity $\left([\theta]_{222 \mathrm{~nm}}\right.$ in $\left.\mathrm{cm}^{2} \mathrm{deg} \mathrm{dmol}^{-1}\right)=(\mathrm{millidegrees} \times \mathrm{mean}$ residue weight)/(path length in millimetres $\times$ concentration of polypeptide in $\left.\mathrm{mg} \mathrm{ml}^{-1}\right)^{39,40}$. (b) The $\mathrm{pH}$ dependence of the residue molar ellipticity at $222 \mathrm{~nm}$ for $(\mathrm{PAHG})_{57,}(\mathrm{PVBLG}-1)_{60}(\mathrm{PVBLG}-6)_{44,}(\mathrm{PVBLG}-7)_{40}$ and $(\mathrm{PLL})_{75}$. (c) Concentration dependence of residue molar ellipticity at $222 \mathrm{~nm}$ for $(\mathrm{PAHG})_{57}$ and (PVBLG-1) ${ }_{60}$ at pH 3. (d) Temperature dependence of residue molar ellipticity at $222 \mathrm{~nm}$ for $(\mathrm{PAHG})_{57}$ and $(\mathrm{PVBLG}-1)_{60}$ at pH 3. (e) Salt concentration dependence of residue ellipticity at $222 \mathrm{~nm}$ for (PAHG) $)_{57}$ and (PVBLG-1) $)_{60}$ at pH 3 and (PLL) $)_{75}$ at pH 10. (f) The helical stabilities of $(\mathrm{PAHG})_{57}$ and $(\mathrm{PVBLG}-\mathbf{1})_{60}$ at $\mathrm{pH} 3$ and $(\mathrm{PLL})_{75}$ at $\mathrm{pH} 10$ in the presence of urea. (g) CD spectra of (PVBLG-1) $)_{60}(\mathrm{PVBLG}-\mathbf{6})_{44}$ and $(\mathrm{PVBLG}-\mathbf{7})_{40}$. (h) CD spectra of (PVBLG-1) $)_{60}$ in a mixed solvent of MSA and $\mathrm{H}_{2} \mathrm{O}$. (i) Fourier-transform infrared spectra of (PVBLG-1) ${ }_{10}$ and $(P V B L G-1)_{267}$. Infrared spectra were recorded on a Perkin Elmer 100 serial FTIR spectrophotometer (Perkin Elmer) equipped with universal attenuated total reflectance (ATR), which enabled the analysis of PVBLG in powder form. (PVBLG-1) 10 and (PVBLG-1) $)_{267}$ were purified by dialysis and lyophilized. The fluffy samples were placed on the crystal of the sampling accessory for ATR analysis.

remained unchanged when the solution's $\mathrm{pH}$ was increased from 1 to 10 (Fig. 3b). At further increased $\mathrm{pH}$ values, (PVBLG-1) ${ }_{60}$ became less soluble because of deprotonation of its charged secondary amine groups. As with $\mathrm{PAHG}_{57}$, (PVBLG-1) $)_{60}$ showed a lack of concentration dependence of its $-[\theta]_{222}$ and $-[\theta]_{208}$ values in helixforming conditions, suggesting that it remains monomeric in solution (Fig. 3c, Supplementary Fig. S16). It has excellent helical stability against elevated temperatures, with its $-[\theta]_{222}$ value decreasing 
$21 \%$ from $31,700 \mathrm{~cm}^{2} \mathrm{deg} \mathrm{dmol}^{-1}$ at $4{ }^{\circ} \mathrm{C}$ to $25,100 \mathrm{~cm}^{2} \mathrm{deg} \mathrm{dmol}^{-1}$ at $70^{\circ} \mathrm{C}$ (Fig. 3d, Supplementary Fig. S17), and against helix-destabilizing conditions such as high concentrations of $\mathrm{NaCl}$ (Fig. 3e), urea (Fig. 3f) and methanesulfonic acid (MSA; Fig. 3h; Supplementary Figs S18-S20). PVBLG-1 has unprecedented helical stability against any known $\alpha$-peptides and can maintain 76 and $58 \%$ of its original helical contents in $6 \mathrm{M}$ urea and 69\% MSA, respectively. Interestingly, the urea-mediated helix-destabilization experiments do not show the typical helix-to-random coil two-state transition, whereas the MSA-induced denaturation experiments do seem to be consistent with the two-state model with an isodichroic point around $203 \mathrm{~nm}$ (ref. 31; Supplementary Figs S19-S20), suggesting the denaturization mechanisms in urea and MSA are different. The $-[\theta]_{222}$ value of low-MW PVBLG-1's (below 60mer) is strongly correlated with the length of the polymer, and is gradually plateaued at around $32,000 \sim 33,000 \mathrm{~cm}^{2} \mathrm{deg} \mathrm{dmol}-1$ ( $>90 \%$ helical contents) for PVBLG1's with MWs beyond 60mer (Table 1; Supplementary Fig. S21). PVBLG-1's with very low MW, such as (PVBLG-1) $)_{10}$, have mixed conformations containing both $\alpha$-helices and $\beta$-sheets in solid state based on the Fourier-transform infrared analysis (Fig. 3i).

We exploited this strategy for the synthesis of PVBLG $\alpha$ HPEs with various other motifs on the helix surface (Supplementary Figs S22-S27). Amine-containing alcohols (1-amino-2-butanol (2) and 3-amino-1,2-dipropanol (3)), pyridines (4-(aminomethyl)pyridine
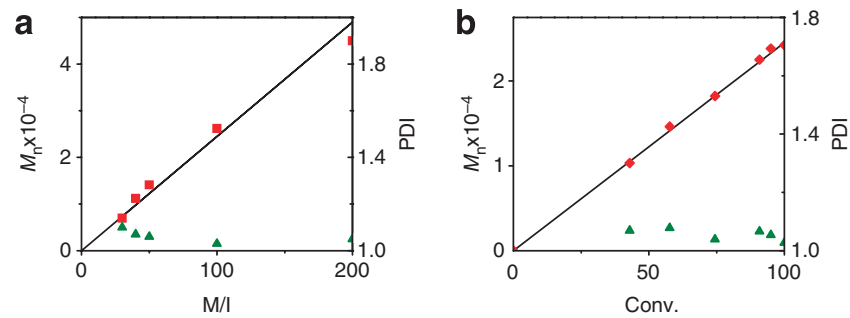

Figure 4 | Controlled polymerization of VB-Glu-NCA. (a) The molecular weights (MWs) and polydispersities (PDIs) of PVBLGs derived from the ROP of VB-Glu-NCA initiated by hexamethyldisilazane at various monomer-to-initiatior (M/I) ratios in DMF (containing 5\% nitrobenzene). (b) The MWs and PDIs at various VB-Glu-NCA conversions at an M/I ratio of 100:1 in DMF (containing 5\% nitrobenzene). The black curve indicates the correlation of the theoretical $\mathrm{MW}$ with the $\mathrm{M} / \mathrm{I}$ ratio in a or with the conversion of VB-Glu-NCA in $\mathbf{b}$; the obtained MWs are denoted as the red squares in both $\mathbf{a}$ and $\mathbf{b}$; the PDIs are denoted as the green triangules in both $\mathbf{a}$ and $\mathbf{b}$
(4) and nicotinic hydrazide (5)), a crown ether (4-aminobenzo18-crown-6 (6)) and a carbohydrate (D-glucosamine (7)) were selected to make the corresponding PVBLG- $\boldsymbol{X}(\boldsymbol{X}=\mathbf{2 - 7}) \alpha$ HPEs. The grafting efficiencies for all of the PVBLG- $\boldsymbol{X}$ s are excellent (>95\%), except for (PVBLG-7) ${ }_{40}$, which has a grafting efficiency of $70 \%$ presumably because of the increased steric bulk of the carbohydrate molecules (Table 1). All of the PVBLG-Xs are water soluble and adopt $\alpha$-helical conformations with minima at 208 and $222 \mathrm{~nm}$ for their CD spectra (Fig. 3g and Supplementary Figs S28-S33). Interestingly, (PVBLG-4) 40 and (PVBLG-6) ${ }_{44}$ showed comparable or even larger $-[\theta]_{222}$ values and helical contents as compared with (PVBLG-1 $_{40}$, confirming our hypothesis that the physicochemical properties and size of the moieties attached to the amine situated distally from the polypeptide backbone have negligible effects on the helical stability of the $\alpha$ HPEs. PVBLG $\alpha$ HPEs containing pyridine, crown ether or sugar on the side chain all adopt very stable helical structures in water, demonstrating the robustness of this strategy in generating water-soluble rod-like $\alpha$ HPEs. It should be noted that the pyridine residues on the side chains of PVBLG-4 are likely protonated at low $\mathrm{pH}$ (lower than the $\mathrm{pKa}$ of pyridine, which is around 5-6). Therefore, the CD spectrum of PVBLG-4 recorded at $\mathrm{pH} \mathrm{3,} \mathrm{which} \mathrm{showed} \mathrm{characteristic} \mathrm{two} \mathrm{minima,} \mathrm{suggests} \mathrm{that}$ polypeptides containing two charges per residue can still adopt stable helical conformation in aqueous solution (Supplementary Fig. S31). PVBLG-2 to -7 also showed a helical stability similar to that of PVBLG-1 against changes in the $\mathrm{pH}$, temperature and salt and in the presence of denaturing reagents, as exemplified by (PVBLG-6) $_{44}$, which showed remarkable stability at various $\mathrm{pH}$ conditions (Fig. 3b).

\section{Discussion}

Polypeptide bearing charged side chains, such as PLG and PLL, typically adopt random coil conformations. These polypeptide electrolytes have been intensively studied for their chemicophysical properties and broadly used in various applications. For instance, they have been used as vehicles in drug and gene delivery ${ }^{32,33}$, as the building blocks of self-assembly ${ }^{34}$, as the water-soluble domains for preparing hydrogels for tissue engineering applications ${ }^{12}$ and as the coating materials for surface modification ${ }^{35}$. In these applications, the polypeptides were simply treated as polymeric electrolytes; the capability of polypeptides to form rigid, rod-like $\alpha$-helical structures, which differentiates polypeptides from many other polyelectrolytes, cannot be used because of the strong helix-destabilizing, sidechain electrostatic repulsions. We hypothesized that polypeptides bearing side-chain charges distally situated from the polypeptide

Table 1 | Synthesis and conformation analysis of PVBLG-X.

\begin{tabular}{|c|c|c|c|c|c|c|c|}
\hline Entry & PABLG & $\begin{array}{l}X \text { (molar } \\
\text { equiv.) }\end{array}$ & $\begin{array}{l}\text { Reducing reagent (molar } \\
\text { equiv.)/reaction time }(\mathrm{h}) / \operatorname{temp}\left({ }^{\circ} \mathrm{C}\right)\end{array}$ & $\begin{array}{c}\text { Product } \\
(\text { PVBLG-X) }\end{array}$ & $\begin{array}{l}\text { Grafting eff. } \\
(\%)\end{array}$ & $\begin{array}{c}-[\theta]_{222} \times 10^{-3} \\
\left(\mathrm{~cm}^{2} \mathrm{deg} \mathrm{dmol}^{-1}\right)\end{array}$ & $\begin{array}{c}\text { Helical } \\
\text { content }(\%) \%\end{array}$ \\
\hline 1 & $\mathrm{PABLG}_{10}$ & $1(3)$ & $\mathrm{NaBH}(\mathrm{OAC})_{3}(5) / 24 / 50$ & $(P \vee B L G-1)_{10}$ & $>95$ & 7.2 & 26.2 \\
\hline 2 & $\mathrm{PABLG}_{40}$ & $1(3)$ & $\mathrm{NaBH}(\mathrm{OAC})_{3}(5) / 24 / 50$ & $(P \vee B L G-1)_{40}$ & $>95$ & 23.1 & 66.9 \\
\hline 3 & $P A B L G_{60}$ & $1(3)$ & $\mathrm{NaBH}(\mathrm{OAc})_{3}(5) / 24 / 50$ & $(P \vee B L G-1)_{60}$ & $>95$ & 32.6 & 91.0 \\
\hline 4 & $P A B L G_{150}$ & $1(3)$ & $\mathrm{NaBH}(\mathrm{OAC})_{3}(5) / 24 / 50$ & $(P \vee B L G-1)_{150}$ & $>95$ & 31.6 & 88.7 \\
\hline 5 & $\mathrm{PABLG}_{180}$ & $1(3)$ & $\mathrm{NaBH}(\mathrm{OAC})_{3}(5) / 24 / 50$ & $(P \vee B L G-1)_{180}$ & $>95$ & 32.9 & 92.1 \\
\hline 6 & $\mathrm{PABLG}_{267}$ & $1(3)$ & $\mathrm{NaBH}(\mathrm{OAc})_{3}(5) / 24 / 50$ & $(P \vee B L G-1)_{267}$ & $>95$ & 32.8 & 91.8 \\
\hline 5 & $\mathrm{PABLG}_{45}$ & $2(3)$ & $\mathrm{NaBH}(\mathrm{OAC})_{3}(5) / 24 / 50$ & $(P \vee B L G-2)_{45}$ & $>95$ & 26.5 & 75.6 \\
\hline 6 & $\mathrm{PABLG}_{45}$ & $3(3)$ & $\mathrm{NaBH}(\mathrm{OAC})_{3}(5) / 24 / 50$ & $(P \vee B L G-3)_{45}$ & $>95$ & 19.7 & 58.2 \\
\hline 7 & $\mathrm{PABLG}_{40}$ & $4(5)$ & $\mathrm{NaBH}(\mathrm{OAc})_{3}(7) / 36 / 50$ & $(P \vee B L G-4)_{40}$ & $>95$ & 23.1 & 66.9 \\
\hline 8 & $\mathrm{PABLG}_{40}$ & $5(3)$ & $\mathrm{NaBH}(\mathrm{OAC})_{3}(5) / 24 / 50$ & $(P \vee B L G-5)_{40}$ & $>95$ & 21.4 & 62.6 \\
\hline 9 & $\mathrm{PABLG}_{20}$ & $6(5)$ & $\mathrm{NaBH}_{4}(5) / 72 /(60-40)^{\star}$ & $(P \vee B L G-6)_{20}$ & $>95$ & 25.3 & 72.6 \\
\hline 10 & $\mathrm{PABLG}_{44}$ & $6(5)$ & $\mathrm{NaBH}_{4}(5) / 72 /(60-40)^{\star}$ & $(P \vee B L G-6)_{44}$ & $>95$ & 33.2 & 92.8 \\
\hline 11 & $\mathrm{PABLG}_{40}$ & $7(10)$ & $\mathrm{NaBH}_{4}(5) / 72 /(60-40)^{\star}$ & $(P \vee B L G-7)_{40}$ & 70 & 27.2 & 77.4 \\
\hline
\end{tabular}

*PABLG was first condensed with the corresponding amine at $60^{\circ} \mathrm{C}$ for $48 \mathrm{~h}$ followed by addition of $\mathrm{NaBH}_{4}$; the mixture was stirred at $40^{\circ} \mathrm{C}$ for $24 \mathrm{~h}$. $\dagger$ The mean residue ellipticity $[\theta]$ was determined

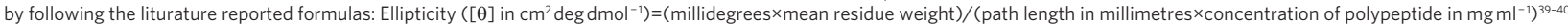


backbones may simultaneously maintain water solubility (because of the charges) and stable helical structures (because of the reduced side-chain electrostatic repulsions (Fig. 1d). To demonstrate this hypothesis, we prepared $\mathrm{PAPG}_{57}, \mathrm{PAPTG}_{50}$ and $\mathrm{PAHG}_{57}$, and compared their conformations against PLL, which is known to adopt random coil conformation in aqueous solution. The conformation analysis using $\mathrm{CD}$ clearly showed that elongating the polypeptide side chains to extend the charge away from polypeptide backbone can indeed allow helical conformation well maintained in polypeptide electrolytes. $\mathrm{PAHG}_{57}$ that has the longest side chains separating the charge and polypeptide backbone adopts the highest helical content among these three tested polypeptides. We found that the hydrophobicity of the charged side chains also has significant effect on the helix stability. PAPTG ${ }_{50}$ contains $\sim 29 \%$ of helical content, whereas $\mathrm{PAEG}_{50}$, which has exactly the same structure as $\mathrm{PAPTG}_{50}$ except that one ' $\mathrm{CH}_{2}$ ' unit of $\mathrm{PAPTG}_{50}$ is replaced by an 'O' in $\mathrm{PAEG}_{50}$, and thus makes PAEG more hydrophilic than PAPTG, adopts completely random coil conformation (Fig. 3a). When polypeptide bearing hydrophilic, charged side chains, the space between the charge and backbone has to be sufficiently long to reduce the helix-destabilizing, electrostatic repulsion force in order for such polypeptide electrolytes to maintain some helical conformations, as shown in the case of PAHEG. However, without hydrophobic side chains to provide critical helix-stabilizing force, simply reducing side-chain electrostatic repulsion force can only give rise to polypeptide electrolytes with low helical contents, evidenced by the weak $\mathrm{CD}$ signal of PAHEG at $222 \mathrm{~nm}$ (Fig. 3a).

To avoid the complex chemistry involved in the synthesis of poly(L-glutamate) analogues with long, charge-containing side chains as shown in Figure 2a, we attempted and successfully synthesized PVBLG- $\boldsymbol{X}$, a class of new $\alpha$ HPEs that contain prolonged, hydrophobic side chains bearing charged amine moieties, using ROP of VB-Glu-NCA followed by the conversion of the pendant vinyl groups to aldehyde groups and subsequent reductive amination of aldehyde groups with the corresponding amino substrates (R-NH ${ }_{2}$; Fig. $2 \mathrm{~b}$ ). All PVBLG-Xs we prepared adopt helical conformations because they contain a sufficiently long, hydrophobic spacer separating the positive charge and the polypeptide backbone. Interestingly, the size and the hydrophobicity/hydrophilicity of ' $\mathrm{R}$ ' group do not seem to dramatically affect the stability of the helical conformation of PVBLG- $\boldsymbol{X}$ (Table 1); our studies showed that ' ${ }^{\prime}$ ' can be hydrocarbon, alcohol, pyridine, saccharide or crown ether, and the corresponding PVBLG- $\boldsymbol{X}$ 's with charged side chains all adopt stable helical conformations in aqueous solution. These findings suggest that the critical helix-stabilizing force is controlled by the hydrophobic interaction of the side-chain segments immediately connected to the $\alpha$-carbon of polypeptide, with length around 11 $\sigma$-bonds for both PAHG and PVBLG systems based on our experimental results. The charge-containing segments that are extended from the long, hydrophobic segments and distally situated from the polypeptide backbone show negligible effect on helical stability and are responsible for the water solubility of the polypeptides. Given that numerous primary amines are commercially available and can be used for the coupling with PABLG (Fig. 2b) to make PVBLG- $\boldsymbol{X}$, a large library of PVBLG-X's bearing various charged side chains can potentially be generated using this approach.

In conclusion, we discovered that the length of the charged polypeptide side chains is crucial to the stability of the $\alpha$-helical structures of polypeptide. When the side chains become sufficiently long and the charge groups are placed distally from the polypeptide backbone, the substantially reduced charge density on the helix surface causes the charge repulsion force to no longer be dominating and helix-disrupting. Our study indicated that polypeptides containing both hydrophobic and hydrophilic side chains with distally situated terminal charge groups can adopt helical conformations, but only polypeptides with long hydrophobic side chains show high helical contents. For polypeptide electrolytes with sufficiently long hydrophobic side chains (substantially reduced sidechain charge repulsion forces), side-chain hydrophobic interactions dominate to drive the formation of water-soluble, helical structures with remarkable helical stability despite changes in the $\mathrm{pH}$ or temperature and against various strong denaturing reagents. Our discovery may also explain why nature has not evolved to use amino acids with long, charged side chains as the building blocks for constructing proteins. As the reversibility of $\alpha$-helix folding/unfolding is critical to many important biological processes, the incorporation of amino-acid residues bearing long, charged, hydrophobic side chains would have made the $\alpha$-helix structure too stable to unfold. The simple polymerization method we have developed for producing helical, water-soluble polypeptides (PVBLG-X) bearing various moieties should find various biological and biomedical applications. We also believe that the strategy of reducing helical surface charge density by incorporating amino acids with elongated, charged side chains can be generally applied to the design of sequence-specific peptides with highly stable helical conformations.

\section{Methods}

Synthesis of PAHG. Synthesis of poly(L-glutamic acid) PLG ${ }_{57}$. Poly $(\gamma$-benzyl-Lglutamate) (PBLG) with a degree of polymerization of $57\left(\mathrm{PBLG}_{57}\right)$ was synthesized by following the procedure previously reported ${ }^{27}$. The $M_{\mathrm{n}}$ is $12,500 \mathrm{~g} \mathrm{~mol}^{-1}$ and PDI $\left(M_{\mathrm{w}} / M_{\mathrm{n}}\right)$ is 1.15 as characterized by gel permeation chromatograph (GPC). The deprotection of $\mathrm{PBLG}_{57}$ was performed at $0{ }^{\circ} \mathrm{C}$ to give $\mathrm{PLG}_{57}$ in quantitative yield by following a slightly modified, standard procedure ${ }^{36-38}$. The resulting polymer $(500 \mathrm{mg})$ was treated with $2 \mathrm{M} \mathrm{NaOH}(10 \mathrm{ml})$ and then with $\mathrm{CBZ}-\mathrm{Cl}(0.1 \mathrm{ml})$ for $16 \mathrm{~h}$ to protect the amino terminus of PLG with CBZ. The resulting PLG was acidified by $3 \mathrm{M} \mathrm{HCl}$. The precipitates were purified subsequently by dialysis against deionized water followed by lyophilization. ${ }^{1} \mathrm{H}$ nuclear magnetic resonance (NMR; trifluoroacetic acid (TFA)- $d, 500 \mathrm{MHz}): \delta 4.86(1 \mathrm{H}, \alpha \mathrm{H}), 2.68(2 \mathrm{H}, \gamma \mathrm{H})$, $2.34(1 \mathrm{H}, \beta \mathrm{H})$ and $2.19(1 \mathrm{H}, \beta \mathrm{H})$.

Synthesis of 6-( $\mathrm{N}$-Boc-amino)-1-hexanol. 6-Amino-1-hexanol (1.17 g, $10 \mathrm{mmol}$ ) was dissolved in chloroform $(15 \mathrm{ml})$ and stirred in an ice bath. (Boc) $)_{2} \mathrm{O}$ $(2.25 \mathrm{~g}, 10.8 \mathrm{mmol})$ was added to the mixture in a small portion for about $5 \mathrm{~min}$. The reaction mixture was stirred in the ice bath for another $2 \mathrm{~h}$ before the solvent was removed under vacuum. The crude product was recrystallized with hexane to give pure 6-(N-Boc amino)-1-hexanol (1.95 g, 90\% yield). ${ }^{1} \mathrm{H} \mathrm{NMR}\left(\mathrm{CDCl}_{3}\right.$, $500 \mathrm{MHz}): \delta 4.58(\mathrm{~s}, 1 \mathrm{H}, \mathrm{NH}), 3.62\left(\mathrm{t}, 2 \mathrm{H}, J=8.0 \mathrm{~Hz},-\mathrm{CH}_{2} \mathrm{CH}_{2} \mathrm{CH}_{2} \mathrm{CH}_{2} \mathrm{OH}\right)$, $3.15\left(\mathrm{t}, 2 \mathrm{H}, J=7.5 \mathrm{~Hz}, \mathrm{BocNHCH}{ }_{2} \mathrm{CH}_{2}\right), 1.77\left(\mathrm{~S}, 1 \mathrm{H},-\mathrm{CH}_{2} \mathrm{CH}_{2} \mathrm{CH}_{2} \mathrm{CH}_{2} \underline{\mathrm{OH}}\right)$, $1.60-1.30\left(\mathrm{~m}, 17 \mathrm{H},\left(\underline{\mathrm{CH}}_{3}\right)_{3} \mathrm{C}(\mathrm{CO}) \mathrm{NHCH}_{2} \mathrm{CH}_{2} \underline{\mathrm{CH}}_{2} \mathrm{CH}_{2} \underline{\mathrm{CH}}_{2} \mathrm{CH}_{2} \mathrm{OH}\right) .{ }^{13} \mathrm{C} \mathrm{NMR}$ $\left(\mathrm{CDCl}_{3}, 500 \mathrm{MHz}\right): \delta 156.0,79.0,62.6,40.3,32.5,30.2,28.4,26.3,25.2$.

Synthesis of PAHG: PLG $_{57}(25 \mathrm{mg}, 0.20 \mathrm{mmol}$ Glu repeating unit), bis(2-oxo3-oxazolidinyl)phosphonic chloride (BOP-Cl) (350 mg, $1.37 \mathrm{mmol})$, 4-dimethylaminopyridine (DMAP) $(17 \mathrm{mg}, 0.14 \mathrm{mmol})$, anhydrous triethylamine $(0.2 \mathrm{ml}$, $1.4 \mathrm{mmol})$ and 6 -( $N$-Boc amino $)-1$-hexanol $(440 \mathrm{mg}, 2 \mathrm{mmol})$ were added in anhydrous $N$-methylpyrrolidone $(4 \mathrm{ml})$ under nitrogen in an ice bath. The conjugation reaction was allowed to proceed at $40-50^{\circ} \mathrm{C}$ for 3 days. Ethyl acetate $(30 \mathrm{ml})$ and a brine solution $(20 \mathrm{ml})$ were added to the reaction mixture. The organic phase was washed with $\mathrm{NaHCO}_{3}(1 \mathrm{M}, 10 \mathrm{ml})$ and $\mathrm{DI}$ water $(2 \times 15 \mathrm{ml})$, dried with $\mathrm{Na}_{2} \mathrm{SO}_{4}$, and concentrated under vacuum. An oily residue was yielded, which was washed by ether $(3 \times 10 \mathrm{ml})$ to remove the excess $6-(N-B) c)-1$-hexanol. The residue was dissolved in chloroform; TFA was added to the solution at room temperature. The mixture was stirred overnight, concentrated under vacuum to yield the deprotected

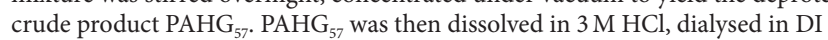
water and lyophilized (22 mg, $43 \%$ overall yield). The grafting efficiency was $95 \%$ as calculated from ${ }^{1} \mathrm{H}$ NMR spectrum (Supplementary Fig. S3). PAPG, PAPTG, PAEG and PAHEG were similarly prepared and characterized (see Supplementary Figs S1, S2, S10 and S11, respectively).

Synthesis of PVBLG- $\boldsymbol{X}(\boldsymbol{X}=\mathbf{1 - 7})$. Synthesis of $\gamma$-(4-vinylbenzyl)-L-glutamate NCA (VB-Glu-NCA). $\gamma$-(4-Vinylbenzyl)-L-glutamate (VB-Glu) was synthesized by following a modified procedure ${ }^{30}$. VB-Glu $(2.45 \mathrm{~g}, 10 \mathrm{mmol})$ was dried under vacuum for $2 \mathrm{~h}$. This solid was suspended in anhydrous THF $(30 \mathrm{ml})$. Phosgene (20\% in toluene, $7 \mathrm{ml}$ ) was added under nitrogen to the solution dropwise for $5 \mathrm{~min}$. The suspension was stirred at $50^{\circ} \mathrm{C}$ for $2-3 \mathrm{~h}$. The solvent was then removed under vacuum. The residue was dissolved in anhydrous THF in a glove box and centrifuged to remove the unreacted amino acid. The supernatant was combined and then the solvent was removed under vacuum. The residue was dissolved in THF $(10 \mathrm{ml})$ followed by the addition of anhydrous ether $(100 \mathrm{ml})$. The solution was cooled at $-30^{\circ} \mathrm{C}$ in the glove box. A dark oily residue was removed. The clear solution containing NCA was combined and concentrated. VB-Glu-NCA in white crystalline form $(3.4 \mathrm{mmol}, 1.0 \mathrm{~g}, 34 \%)$ was obtained through recrystallization three times using THF/hexane. ${ }^{1} \mathrm{H} \mathrm{NMR}\left(\mathrm{CDCl}_{3}, 500 \mathrm{MHz}\right): \delta 7.40(\mathrm{~d}, 2 \mathrm{H}, J=8.0 \mathrm{~Hz}$, 
ArH $\underline{H}, 7.30(\mathrm{~d}, 2 \mathrm{H}, J=8 \mathrm{~Hz}, \mathrm{Ar} \underline{\mathrm{H}}), 6.73-6.67\left(\mathrm{~m}, 2 \mathrm{H}, \mathrm{NH}^{\mathrm{H}}\right.$ and $\left.\mathrm{C}_{6} \mathrm{H}_{4} \mathrm{CH}=\mathrm{CH}_{2}\right), 5.76$ $\left(\mathrm{d}, 1 \mathrm{H}, J=17.5 \mathrm{~Hz}, \mathrm{C}_{6} \mathrm{H}_{4} \mathrm{CH}=\underline{\mathrm{CH}}_{2}\right), 5.27\left(\mathrm{~d}, 1 \mathrm{H}, J=11 \mathrm{~Hz}, \mathrm{C}_{6} \mathrm{H}_{4} \mathrm{CH}=\mathrm{CH}_{2}\right), 5.11$ (s, $\left.2 \mathrm{H}, \mathrm{ArCH}_{2}\right), 4.38\left(\mathrm{t}, 1 \mathrm{H}, J=6.0 \mathrm{~Hz}, \mathrm{CHCH}_{2} \mathrm{CH}_{2} \mathrm{COOCH}_{2}\right), 2.58\left(\mathrm{t}, 2 \mathrm{H}, \mathrm{CH}_{2}\right.$ $\left.\mathrm{CH}_{2} \mathrm{COOCH}_{2}\right), 2.26\left(\mathrm{~m}, 1 \mathrm{H}, \underline{\mathrm{CH}}_{2} \mathrm{CH}_{2} \mathrm{COOCH}_{2}\right), 2.12\left(\mathrm{~m}, 1 \mathrm{H}, \underline{\mathrm{CH}}_{2} \mathrm{CH}_{2} \mathrm{COOCH}_{2}\right)$ ${ }^{13} \mathrm{C}$ NMR $\left(\mathrm{CDCl}_{3}, 500 \mathrm{MHz}\right): \delta 172.4,169.3,151.9,137.8,136.1,134.6,128.6,126.4$, $114.6,66.8,56.9,29.8,26.8$. Electrospray ionization mass spectrometry (ESI MS) analysis (with $\mathrm{NaCl}$ ) calcd: $m / z 289.2(\mathrm{M})$; found: $m / z 312.3(\mathrm{M}+\mathrm{Na}$ ). Analysis calculated for $\mathrm{C}_{15} \mathrm{H}_{15} \mathrm{NO}_{5}: 62.29 \% \mathrm{C}, 5.21 \% \mathrm{H}, 4.84 \% \mathrm{~N}$; found: $62.06 \% \mathrm{C}, 5.12 \%$ $\mathrm{H}, 4.83 \% \mathrm{~N}$.

General procedure for the polymerization of VB-Glu-NCA . In a glove box, VB-Glu-NCA ( $29 \mathrm{mg}, 0.1 \mathrm{mmol}$ ) was dissolved in the mixture of DMF (1 ml) and nitrobenzene $(50 \mu \mathrm{l}$; nitrobenzene was used to inhibit potential radical reactions on vinyl group). The VB-Glu-NCA solution was added to a DMF solution of hexamethyldisilazane $\left(20 \mu \mathrm{l}, 0.1 \mathrm{mmol} \mathrm{ml}^{-1}\right)$. The reaction mixture was stirred for $15 \mathrm{~h}$ at room temperature. An aliquot of the polymerization solution was diluted to $10 \mathrm{mg}$ PVBLG per $\mathrm{ml}$ using DMF (containing $0.1 \mathrm{M} \mathrm{LiBr}$ ), and then analysed by GPC. The $M_{\mathrm{n}}$ and PDI were assessed by GPC $\left(M_{\mathrm{n}}=26,200 \mathrm{~g} \mathrm{~mol}^{-1}\right.$, PDI $\left.\left(M_{w} / M_{n}\right)=1.03\right)$. The remaining PVBLG was precipitated with ether $(15 \mathrm{ml})$. The obtained PVBLG was sonicated for $5 \mathrm{~min}$ in ether and centrifuged to remove the solvent. After the sonication-centrifugation procedure was repeated two more times, PVBLG was collected and dried under vacuum ( $>95 \%$ yield). ${ }^{1} \mathrm{H}$ NMR (TFA- $d, 500 \mathrm{MHz}$ ): $\delta 7.53$ (d, $2 \mathrm{H}, J=7.0 \mathrm{~Hz}, \operatorname{Ar} \underline{\mathrm{H}}), 7.39$ (d, $2 \mathrm{H}, J=7.0 \mathrm{~Hz}, \mathrm{Ar} \underline{\mathrm{H}}$ ), $6.84\left(\mathrm{dd}, 1 \mathrm{H}, J_{1}=11.0 \mathrm{~Hz}, J_{2} 18.0 \mathrm{~Hz} \mathrm{C}_{6} \mathrm{H}_{4} \mathrm{CH}=\mathrm{CH}_{2}\right), 5.91(\mathrm{~d}, 1 \mathrm{H}, J=18.0 \mathrm{~Hz}$, $\left.\mathrm{C}_{6} \mathrm{H}_{4} \mathrm{CH}=\underline{\mathrm{C}}_{2}\right), 5.43\left(\mathrm{~d}, 1 \mathrm{H}, J=11.0 \mathrm{~Hz}, \mathrm{C}_{6} \mathrm{H}_{4} \mathrm{CH}=\underline{\mathrm{CH}}_{2}\right), 5.26\left(\mathrm{~m}, 2 \mathrm{H}, \mathrm{ArCH}_{2}\right)$, $4.80\left(\mathrm{~m}, 1 \mathrm{H}, \mathrm{CHCH}_{2} \mathrm{CH}_{2} \mathrm{COOCH}_{2}\right), 2.68\left(\mathrm{~m}, 2 \mathrm{H}, \mathrm{CHCH}_{2} \mathrm{CH}_{2} \mathrm{COO}\right), 2.30(\mathrm{~m}, 1 \mathrm{H}$, $\mathrm{CHCH}_{2} \mathrm{CH}_{2} \mathrm{COO}$ ), 2.12 (m, 1H, $\mathrm{CHCH}_{2} \mathrm{CH}_{2} \mathrm{COO}$ ) (Supplementary Fig. S12).

Synthesis of PABLG. PVBLG $(10 \mathrm{mg})$ was dissolved in chloroform $(10 \mathrm{ml})$ at $-78^{\circ} \mathrm{C}$ and $\mathrm{O}_{2}$ was bubbled into the solution for $1 \mathrm{~min}$, followed by bubbling of $\mathrm{O}_{3}$ until the solution became blue. $\mathrm{O}_{3}$ was then replaced by $\mathrm{O}_{2}$, which was bubbled into the solution for another 2 min until the solution became colourless. The solution was then degassed and back filled with nitrogen. $\mathrm{Ph}_{3} \mathrm{P}(26 \mathrm{mg})$ was then added to the mixture. The solution was stirred at room temperature for $2-3 \mathrm{~h}$ The solvent was then removed under vacuum. The resulting PABLG was purified by sonicating the polymer in methanol $(3 \times 15 \mathrm{ml})$ to remove the unreacted $\mathrm{Ph}_{3} \mathrm{P}$ and other impurities. ${ }^{1} \mathrm{H}$ NMR (TFA- $\left.d, 500 \mathrm{MHz}\right): \delta 10.31\left(1 \mathrm{H}, \mathrm{CHOC}_{6} \mathrm{H}_{4}\right), 8.40$ $(\mathrm{d}, 2 \mathrm{H}, J=7.0 \mathrm{~Hz}, \mathrm{ArH}), 7.96(\mathrm{~d}, 2 \mathrm{H}, J=7.0 \mathrm{~Hz}, \mathrm{ArH}), 5.71\left(2 \mathrm{H}, \mathrm{CHOC}_{6} \mathrm{H}_{4} \mathrm{CH}_{2}\right)$, $5.21\left(1 \mathrm{H}, \mathrm{CHCH}_{2} \mathrm{CH}_{2} \mathrm{CO}_{2} \mathrm{CH}_{2}\right), 3.12\left(2 \mathrm{H}, \mathrm{CHCH}_{2} \mathrm{CH}_{2}\right), 2.75\left(1 \mathrm{H}, \mathrm{CHCH}_{2} \mathrm{CH}_{2}\right)$, $2.56\left(1 \mathrm{H}, \mathrm{CHCH}_{2} \mathrm{CH}_{2}\right)$ (Supplementary Fig. S13).

Synthesis of PVBLG- $\boldsymbol{X}(\boldsymbol{X}=1-7)$. The PABLG (20 mg), amine (3-5 molar equiv. relative to the Glu repeating unit) and the reducing reagent (5-10 molar equiv.; Table 1) were mixed in THF ( $3 \mathrm{ml}$; except for 7 with DMF was used as the solvent). The reaction mixtures were stirred at $50-60{ }^{\circ} \mathrm{C}$ for $24-72 \mathrm{~h}$ (Table 1 ). The mixture was then poured into $3 \mathrm{M} \mathrm{HCl}(3 \mathrm{ml})$, followed by dialysis against water and lyophilization. The yields of the products PVBLG- $\boldsymbol{X}(\boldsymbol{X}=\mathbf{1 - 7})$ were around $50-75 \%$ after dialysis. The grafting efficiencies were analysed by ${ }^{1} \mathrm{H}$ NMR (Supplementary Figs S14, S22-S27).

General procedure for the analysis of polypeptide conformations by $\mathrm{CD}$. The CD experiments were conducted on a JASCO J-700 or a JASCO J-720 CD spectrometer. The polypeptide samples were generally prepared at concentrations of $0.01-0.1 \mathrm{mg} \mathrm{ml}^{-1}$ at $\mathrm{pH} 3$ unless otherwise specified. The solution was placed in a quartz cell with a path length of $0.2 \mathrm{~cm}$. The mean residue molar ellipticity of each polymer was calculated on the basis of the measured apparent ellipticity by following the literature-reported formulas: Ellipticity $\left([\theta]\right.$ in $\left.\mathrm{cm}^{2} \mathrm{deg} \mathrm{dmol}^{-1}\right)$ $=($ millidegrees $\times$ mean residue weight $) /($ path length in millimetres $\times$ concentration of polypeptide in $\left.\mathrm{mg} \mathrm{ml}^{-1}\right)^{39,40}$. For the temperature-dependent experiments, the temperature of the sample chamber (where the quartz cell was placed) was controlled by a water bath (from $4^{\circ} \mathrm{C}$ to $70^{\circ} \mathrm{C}$ ). The samples were equilibrated at the corresponding temperature for at least $10 \mathrm{~min}$ before the $\mathrm{CD}$ measurements. By following similar preparation method, the polymers were dissolved in DI water or in a solution containing $\mathrm{NaCl}$, urea or MSA. For the $\mathrm{pH}$-dependent experiments, the $\mathrm{pH}$ of the polymer solution was tuned by the addition of a concentrated $\mathrm{HCl}$ or $\mathrm{NaOH}$ solution. The $\alpha$-helix contents of the polypeptides were calculated by the following equation: percentage of $\alpha$-helix $=\left(-\left[\theta_{222}\right]+\right.$ $3,000) / 39,000^{28}$.

\section{References}

1. Stryer, L. Biochemistry 4th edn (W.H. Freeman and Company, 1998)

2. Robertson, D. E. et al. Design and synthesis of multi-heme proteins. Nature 368, 425-431 (1994)

3. Munoz, V. \& Serrano, L. Elucidating the folding problem of helical peptides using empirical parameters. Nat. Struct. Biol. 1, 399-409 (1994).

4. Goodman, C. M., Choi, S., Shandler, S. \& DeGrado, W. F. Foldamers as versatile frameworks for the design and evolution of function. Nat. Chem. Biol. 3, 252-262 (2007).

5. Fiori, W. R., Lundberg, K. M. \& Millhauser, G. L. A single carboxy-terminal arginine determines the amino-terminal helix conformation of an alaninebased peptide. Nat. Struct. Biol. 1, 374-377 (1994).

6. Fezoui, Y. et al. A de novo designed helix-turn-helix peptide forms nontoxic amyloid fibrils. Nat. Struct. Biol. 7, 1095-1099 (2000).
7. Drin, G. et al. A general amphipathic alpha-helical motif for sensing membrane curvature. Nat. Struct. Mol. Biol. 14, 138-146 (2007).

8. Bryson, J. W. et al. Protein design: a hierarchic approach. Science 270, 935-941 (1995).

9. Bang, D. et al. Dissecting the energetics of protein alpha-helix C-cap termination through chemical protein synthesis. Nat. Chem. Biol. 2, 139-143 (2006)

10. Zhang, S. G. Fabrication of novel biomaterials through molecular self-assembly. Nat. Biotechnol. 21, 1171-1178 (2003).

11. Hartgerink, J. D., Beniash, E. \& Stupp, S. I. Self-assembly and mineralization of peptide-amphiphile nanofibers. Science 294, 1684-1688 (2001).

12. Nowak, A. P. et al. Rapidly recovering hydrogel scaffolds from self-assembling diblock copolypeptide amphiphiles. Nature 417, 424-428 (2002).

13. Chakrabartty, A., Kortemme, T. \& Baldwin, R. L. Helix propensities of the amino acids measured in alanine-based peptides without helix-stabilizing sidechain interactions. Protein Sci. 3, 843-852 (1994).

14. Levy, Y., Jortner, J. \& Becker, O. M. Solvent effects on the energy landscapes and folding kinetics of polyalanine. Proc. Natl Acad. Sci. USA 98, 2188-2193 (2001).

15. Dobson, C. M., Sali, A. \& Karplus, M. Protein folding: a perspective from theory and experiment. Angew. Chem. Int. Ed. 37, 868-893 (1998).

16. Munoz, V., Blanco, F. J. \& Serrano, L. The hydrophobic-staple motif and a role for loop-residues in alpha-helix stability and protein folding. Nat. Struct. Biol. 2, 380-385 (1995).

17. Dobson, C. M. Protein folding and misfolding. Nature 426, 884-890 (2003).

18. Dill, K. A. Diminant forces in protein folding. Biochemistry 29, 7133-7155 (1990).

19. Marqusee, S. \& Baldwin, R. L. Helix stabilization by Glu-.Lys+ salt bridges in short peptides of de novo design. Proc. Natl Acad. Sci. USA 84, 8898-8902 (1987).

20. Blackwell, H. E. \& Grubbs, R. H. Highly efficient synthesis of covalently crosslinked peptide helices by ring-closing metathesis. Angew. Chem. Int. Ed. 37, 3281-3284 (1998).

21. Lotan, N., Yaron, A. \& Berger, A. Stabilization of alpha-helix in aqueous solution by hydrophobic side-chain interaction. Biopolymers 4, 365-368 (1966)

22. Yu, M., Nowak, A. P., Deming, T. J. \& Pochan, D. J. Methylated mono- and diethyleneglycol functionalized polylysines: nonionic, alpha-helical, watersoluble polypeptides. J. Am. Chem. Soc. 121, 12210-12211 (1999).

23. Lyu, P. C., Sherman, J. C., Chen, A. \& Kallenbach, N. R. Alpha-helix stabilization by natural and unnatural amino-acids with alkyl side chains. Proc. Natl Acad. Sci. USA 88, 5317-5320 (1991).

24. Pace, C. N. \& Scholtz, J. M. A helix propensity scale based on experimental studies of peptides and proteins. Biophys. J. 75, 422-427 (1998).

25. Lu, H. \& Cheng, J. $N$-trimethylsilyl amines for controlled ring-opening polymerization of amino acid $\mathrm{N}$-carboxyanhydrides and facile end group functionalization of polypeptides. J. Am. Chem. Soc. 130, 12562-12563 (2008).

26. Lu, H., Wang, J., Lin, Y. \& Cheng, J. One-pot synthesis of brush-like polymers via integrated ring-opening metathesis polymerization and polymerization of amino acid N-carboxyanhydrides. J. Am. Chem. Soc. 131, 13582-13583 (2009).

27. Lu, H. \& Cheng, J. Hexamethyldisilazane-mediated controlled polymerization of alpha-Amino acid N-carboxyanhydrides. J. Am. Chem. Soc. 129, 1411414115 (2007).

28. Morrow, J. A. et al. Differences in stability among the human apolipoprotein $\mathrm{E}$ isoforms determined by the amino-terminal domain. Biochemistry 39, 11657-11666 (2000).

29. Luijten, J., Groeneveld, D. Y., Nijboer, G. W., Vorenkamp, E. J. \& Schouten, A. J. Cross-linking-induced permanently perpendicular helix orientation in surfacegrafted polyglutamate films. Langmuir 23, 8163-8169 (2007).

30. Vanheeswijk, W. A. R., Eenink, M. J. D. \& Feijen, J. An improved method for the preparation of gamma-esters of glutamic-acid and beta-esters of asparticacid. Synthesis (Stuttg.) 744-747 (1982).

31. Guerois, R. \& López de la Paz, M. Protein Design: Methods and Applications (Humana Press, 2006).

32. Putnam, D., Gentry, C. A., Pack, D. W. \& Langer, R. Polymer-based gene delivery with low cytotoxicity by a unique balance of side-chain termini. Proc. Natl Acad. Sci. USA 98, 1200-1205 (2001).

33. Bhatt, R. L. et al. Synthesis and in vivo antitumor activity of poly(L-glutamic acid) conjugates of 20(S)-camptothecin. J. Med. Chem. 46, 190-193 (2003).

34. Holowka, E. P., Sun, V. Z., Kamei, D. T. \& Deming, T. J. Polyarginine segments in block copolypeptides drive both vesicular assembly and intracellular delivery. Nat. Mater. 6, 52-57 (2007).

35. Wong, M. S., Cha, J. N., Choi, K. S., Deming, T. J. \& Stucky, G. D. Assembly of nanoparticles into hollow spheres using block copolypeptides. Nano Lett. 2, 583-587 (2002)

36. Wang, Y. L. \& Chang, Y. C. Synthesis and conformational transition of surfacetethered polypeptide: poly(L-lysine). Macromolecules 36, 6511-6518 (2003).

37. Blout, E. R. \& Idelson, M. Polypeptides. VI. Poly-alpha-glutamic acid: preparation and helix-coil conversions. J. Am. Chem. Soc. 78, 497-498 (1956). 
38. Li, J. G. et al. Stimuli-responsive zwitterionic block copolypeptides: $\operatorname{poly}(N-$ isopropylacrylamide)-block-poly(lysine-co-glutamic acid). Biomacromolecules 9, 2670-2676 (2008).

39. Adler, A. J., Greenfield, N. J. \& Fasman, G. D. Circular dichroism and pptical rotatory dispersion of proteins and polypeptides. Methods Enzymol. 27, 675-735 (1973).

40. Greenfield, N. J. Using circular dichroism spectra to estimate protein secondary structure. Nat. Prot. 1, 2876-2890 (2006).

\section{Acknowledgments}

J.C. acknowledges supports from the NSF (CHE-0809420 and DMR-0748834), the NIH (Director's New Innovator Award program 1DP2OD007246-01, 1R21EB009486 A and 1R21CA139329 Z), and the Siteman Centre for Cancer Nanotechnology Excellence-

Centre for Nanoscale Science and Technology. Y.L. acknowledges supports from the US Department of Energy, Office of Basic Energy Sciences, Division of Materials Sciences and Engineering (DE-SC0005039).

\section{Author contributions}

H.L. and J.C. conceived the idea and designed the polypeptides; H.L., Y.B. and J.W.L. synthesized the polypeptides; H.L. and J.W. performed the characterization experiments; J.C., H.L., Y.L., J.W. and S.L. analysed the data and wrote the paper.

\section{Additional information}

Supplementary Information accompanies this paper at http://www.nature.com/ naturecommunications

Competing financial interests The authors declare no competing financial interests.

Reprints and permission information is available online at http://npg.nature. com/reprints andpermissions/.

How to cite this article: $\mathrm{Lu}, \mathrm{H}$. et al. Ionic polypeptides with unusual helical stability. Nat. Commun. 2:206 doi: 10.1038/ncomms1209 (2011). 